\title{
Strengthening public health in Germany: overcoming the Nazi legacy and Bismarck's aftermaths
}

\author{
Oliver Razum ${ }^{1}$ - M. Luisa Vázquez ${ }^{2}$
}

Received: 18 September 2017/ Accepted: 19 September 2017/Published online: 27 September 2017

(c) Swiss School of Public Health (SSPH+) 2017

"Germany and health" is the title of a recent Lancet series examining the country's health-care system (Busse et al. 2017) and its growing engagement in global health (Kickbusch et al. 2017). Interestingly, public health in Germany receives short shrift in this series. Whipped again, one could say, after Germany's public health had recently been criticized by three distinguished national scientific academies-incorrectly so for allegedly weak scientific achievements, but rightly so for structural deficiencies (Künzli 2015; Razum and Jahn 2016).

Why is public health structurally weak in a country that is expected, or even pushed, to become a leader in global health (Kickbusch et al. 2017)? Germany performed strongly in social medicine in the early decades of the twentieth century. During Nazi times, however, health promotion and public health research, e.g., on tobacco, became closely entangled with the dictatorship; smoking thus even turned into an inconspicuous way of expressing opposition toward the government (Davey Smith et al. 1994). Moreover, the Nazi's most hideous crimes were committed by perverting Germany's progressive social hygiene movement into an inhuman "racial hygiene" (Proctor 1996).

Oliver Razum

oliver.razum@uni-bielefeld.de

M. Luisa Vázquez

mlvazquez@consorci.org

1 Department of Epidemiology \& International Public Health, School of Public Health, Bielefeld University, P. O. Box 100131, 33501 Bielefeld, Germany

2 Health Policy and Health Services Research Group, Health Policy Research Unit, Consorci de Salut i Social de Catalunya, Avenida Tibidabo, 21, 08022 Barcelona, Spain
But is history the only reason why Germany lags behind other European countries in public health? We propose that this is also due to the way in which its health system is organized. Germany maintains a model of social security in health (SSH), introduced by Bismarck in 1883, in which statutory health insurance companies provide health-care coverage for their members (Busse et al. 2017). One advantage of the SSH is the high degree of consumer satisfaction it achieves through its pronounced disease orientation and focus on individual patients. This comes at a price: besides high cost, there is little emphasis on promoting and improving health at the population level. Accordingly, Germany's health system is fragmented: public health does not, or only to a small part, fall under SSH responsibility. Population-based preventive and health promotion measures are instead provided by different agencies at the central and federal state level, among them the Robert Koch Institute (RKI) and the Federal Centre for Health Education (BZgA), and by local health authorities.

Other countries organize their health systems differently, along Beveridge's National Health System (NHS) model with tax-based public funding granting universal access to citizens, under the responsibility of national or regional health authorities (van der Zee and Kroneman 2007). Spain, for example, moved from an SSH to an NHS in 1986, followed by a devolution of responsibilities for public health and health-care services to 17 regional health administrations. The regional authorities are largely responsible for health policy, health services planning, management and provision, as well as for public health. The reform comprised a shift from a disease- and individual-oriented model to a primary health-care model focusing on population health. It emphasizes integration of promotion, prevention and rehabilitation activities (Garcia- 
Armesto et al. 2010). Public health schools and associations play an important role in shaping these changes.

The solid performance of public health in NHS countries implies that Germany not only has to come to terms with the moral abyss of its Nazi legacy, but it must also overcome the fragmentation inherent in the Bismarckian SSH to strengthen its public health sector. Recently, there have been renewed efforts in this direction: the "Zukunftsforum Public Health" (forum for the future of public health, http://www.zukunftsforum-public-health.de) provides a platform for exchange among public health actors, including those in academia, NGOs, RKI, BZgA and public health services. The forum counsels politicians on the important role of public health and of Health in All Policies, and it lobbies for more research funding, with an eye on increased political efficacy of public health research (Gerhardus et al. 2016). It is organizing a second national networking conference in 2017. The platform strongly endorses equity as an ethical basis of public health and lobbies for more political attention toward the social determinants of health. It supports the government's global health strategy based on Universal Health Coverage, at the same time reminding politicians that this strategy should also apply at home, for example by removing the entitlement restrictions that refugees currently face when accessing health care in Germany. In parallel to the platform's activities, the German Society for Public Health has changed its statutes to admit individual in addition to institutional members, so that the many new public health graduates from German universities and academies can engage in a vibrant professional network.

Yet, Germany needs to do more to strengthen public health. The ongoing networking efforts are an important start and should be followed by increased funding for public health services and schools of public health. But the public health sector alone will ultimately not be able to overcome the structural boundaries of the present Bismarckean system. Reforms are needed that aim at substantially stronger dovetailing between the curative care and the public health sector. Germany is promoting holistic health system strengthening as part of its global health strategy—so why not also at home?

\section{Compliance with ethical standards}

Conflict of interest Oliver Razum is a member of the steering group of Zukunftsforum Public Health. M. Luisa Vázquez declares no conflict of interest.

\section{References}

Busse R, Blümel M, Knieps F, Bärnighausen T (2017) Statutory health insurance in Germany: a health system shaped by 135 years of solidarity, self-governance, and competition. Lancet 390:882-897. doi:10.1016/S0140-6736(17)31280-1

Davey Smith G, Ströbele SA, Egger M (1994) Smoking and health promotion in Nazi Germany. J Epidemiol Commun Health 48:220-223

Garcia-Armesto S, Abadia-Taira M, Durán A, Hernández-Quevedo C, Bernal-Delgado E (2010) Spain: health system review. Health Syst Transit 12:1-295

Gerhardus A et al (2016) Applying for, reviewing and funding public health research in Germany and beyond. Health Res Policy Syst 14:1-9. doi:10.1186/s12961-016-0112-5

Kickbusch I et al (2017) Germany's expanding role in global health. Lancet 390:898-912. doi:10.1016/S0140-6736(17)31460-5

Künzli N (2015) Trashing epidemiology and public health with bibliometry? In defence of science in Germany (and elsewhere). Int J Public Health 60:877-878. doi:10.1007/s00038-015-0741-4

Proctor RN (1996) Nazi medicine and public health policy dimensions. J Holocaust Stud 10:29-34

Razum O, Jahn A (2016) Molecular and genomic sciences in health: apply the established rules of evidence. Int $\mathrm{J}$ Public Health 61:405-407. doi:10.1007/s00038-015-0755-y

van der Zee J, Kroneman MW (2007) Bismarck or Beveridge: a beauty contest between dinosaurs. BMC Health Serv Res 7:94. doi:10.1186/1472-6963-7-94 